Agronomía Costarricense 45(1): 53-65. ISSN:0377-9424 / 2021

www.mag.go.cr/rev_agr/index.html www.cia.ucr.ac.cr

\title{
TRANSFORMACIONES BIOQUÍMICAS DEL CACAO (Theobroma cacao L.) DURANTE UN PROCESO DE FERMENTACIÓN CONTROLADA
}

\author{
Katherine Rojas-Rojas ${ }^{1}$, Carlos Hernández-Aguirre ${ }^{2 / *}$, Alejandra Mencía-Guevara ${ }^{3}$ \\ Palabras clave: Azúcares; clones; epicatequina; grupos genéticos; metilxantinas. \\ Keywords: Sugars; clones; epicatechin; genetic groups; methylxanthines.
}

Recibido: $23 / 06 / 2020$

Aceptado: 17/08/2020

RESUMEN

Introducción. Las levaduras, las bacterias ácido lácticas y ácido acéticas, involucradas en la fermentación de cacao, son las responsables del consumo de los compuestos en la pulpa para desarrollar los precursores de sabor dentro del grano de cacao. Sin embargo, la fermentación es difícil de controlar por la complejidad de este proceso y las múltiples variables que la afectan, entre ellas la genética del cultivo. Objetivo. Analizar las transformaciones bioquímicas de diferentes grupos genéticos del cacao (Theobroma cacao L.) durante una micro fermentación controlada. Materiales y métodos. Se estableció una metodología de micro fermentación, con un cultivo iniciador de $H$. opuntiae y Acetobacter spp. en 4 grupos genéticos, obtenidos de clones comerciales del CATIE e híbridos de fincas de Upala. A lo largo de la fermentación se analizaron glucosa, fructosa, etanol, ácido láctico y acético en pulpa y metilxantinas (teobromina y cafeína) y (-)-epicatequina en grano. Resultados. No se encontraron diferencias significativas en el contenido y comportamiento de azúcares, ácidos

\footnotetext{
* Autor para correspondencia. Correo electrónico: cherna@una.ac.cr

1 Universidad Nacional de Costa Rica, Escuela de Ciencias Agrarias, Laboratorio de Calidad de Innovación Agroalimentaria, Heredia, Costa Rica. (D) 0000-0003-0075-2256.
}

\begin{tabular}{|c|c|}
\hline \\
\hline \multicolumn{2}{|c|}{$\begin{array}{l}\text { Biochemical transformations of cocoa } \\
\text { (Theobroma cacao L.) during a controlled } \\
\text { fermentation process. Introduction. Yeasts, } \\
\text { lactic acid and acetic acid bacteria, involved } \\
\text { in cocoa fermentation are responsible for } \\
\text { consuming the compounds in the pulp to } \\
\text { develop flavor precursors within the cocoa bean. } \\
\text { However, cocoa fermentation is difficult to } \\
\text { control due to the complexity of this process and } \\
\text { the multiple variables that affect it, including the } \\
\text { genetics of the crop. Objective. To analyze the } \\
\text { biochemical transformations of different genetic } \\
\text { groups of cocoa (Theobroma cacao L.) during a } \\
\text { controlled micro-fermentation. Materials and } \\
\text { methods. A micro-fermentation methodology } \\
\text { was developed with a starter culture of H. } \\
\text { opuntiae and Acetobacter spp. in } 4 \text { genetic } \\
\text { groups, grown in the CATIE Clonal Garden and } \\
\text { hybrids from different farms in the Upala area. } \\
\text { Throughout the fermentation process glucose, } \\
\text { fructose, ethanol, lactic acid and acetic acid } \\
\text { were analyzed in pulp, and methylxanthines } \\
\text { (theobromine and caffeine) and (-)-epicatechin }\end{array}$} \\
\hline & $\begin{array}{l}\text { Universidad Nacional de Costa Rica, Escuela de } \\
\text { Ciencias Agrarias, Laboratorio de Calidad de } \\
\text { Innovación Agroalimentaria, Heredia, Costa Rica. } \\
\text { (DD 0000-0002-0059-8028. }\end{array}$ \\
\hline & \\
\hline
\end{tabular}


orgánicos o etanol en pulpa a lo largo de la fermentación, pero sí en el tiempo de fermentación. Se observó una disminución de metilxantinas y epicatequinas, debido a reacciones enzimáticas y no enzimáticas. El contenido promedio de epicatequina resultó ser el compuesto distintivo entre los grupos genéticos del CATIE y cafeína en los cacaos comerciales. Conclusión. La metodología empleada posee un efecto regulador en el comportamiento de algunos metabolitos estudiados en pulpa de diferentes genéticas a lo largo de la fermentación, así como epicatequina y metilxantinas en grano.

\section{INTRODUCCIÓN}

La especie Theobroma cacao L. (Malvaceae) comprende un gran número de variedades, caracterizadas por una enorme diversidad genética (Bartley 2005). Sin embargo, se acepta que la mayor parte del cacao comercial incluye 3 complejos genéticos: Criollo, Forastero/Amazónico y Trinitario (N'Goran et al. 1994). Hoy en día la clasificación es mucho más amplia estudios realizados por Motamayor et al. (2008) proponen una nueva clasificación del germoplasma de cacao, que comprende 10 grupos principales: Marañón, Curaray, Criollo, Iquitos, Nanay, Contamana, Amelonado, Purús, Nacional y Guayana.

Por otro lado, aspectos como la genética, condiciones ambientales, la fermentación, secado y tostado son factores que afectan la calidad y composición bioquímica del cacao (Kongor et al. 2016). Durante la fermentación, la pulpa que envuelve las semillas es metabolizada por microorganismos que producen cambios bioquímicos, los cuales también afectan los cambios en el $\mathrm{pH}$ por lo que dan origen a transformaciones de aroma, sabor y color del cacao (Contreras et al. 2002). Entre esos cambios bioquímicos destaca in the bean. Results. No significant differences were found in the content and dynamics of sugars, organic acids and ethanol in pulp throughout the fermentation, but differences were found at fermentation time. A decrease in methylxanthines and epicatechin triggered by enzymatic and nonenzymatic reactions was observed. The average epicatechin content proved to be the distinctive compound between CATIE's genetic groups and caffeine in commercial cocoa. Conclusion. The methodology used had a regulatory effect on the behavior of some of the studied metabolites in pulp of different genetic throughout fermentation, as well as epicatechin and methylxanthines in the bean.

la oxidación de polifenoles, específicamente la disminución de la (-) epicatequina y la (+) catequina que es visible a través del desarrollo de la pigmentación marrón (Cros y Jeanjean 1995).

Así pues, varios estudios (Camu et al. 2008a, Keeney y Kim 1984, Lefeber et al. 2011) mencionan que tales compuestos, junto con los alcaloides teobromina y cafeína, contribuyen al amargor y astringencia del chocolate. Algunos estudios confirman el efecto de la fermentación en la calidad sensorial del cacao, asociada a un aumento en el contenido de péptidos, aminoácidos libres y azúcares reductores, precursores del sabor del chocolate, así como de los ácidos orgánicos responsables de las notas de sabor ácidas del cacao (Afoakwa et al. 2008, Schwan y Wheals 2004). El monitoreo de las transformaciones bioquímicas de dichos compuestos, es de gran importancia en el desarrollo de cacaos aptos para la industria chocolatera. Según Oberthür et al. (2011), los mercados internacionales señalan cada vez más la demanda de productos diferenciados de los cuales valoran sus notas sensoriales especiales, que podrían estar asociadas a la interacción de aspectos genéticos (variedades) y bioquímicos (descriptores). 
Por lo tanto, resulta clave el desarrollo de una metodología de micro fermentación en reconocimiento del potencial de variedades particulares. De esta forma, el propósito de la presente investigación fue analizar algunas transformaciones bioquímicas de diferentes grupos genéticos del cacao (Theobroma cacao L.) durante un proceso de micro fermentación controlada.

\section{MATERIALES Y MÉTODOS}

Ubicación del estudio. La fermentación y los análisis químicos se realizaron en el Laboratorio de Calidad e Innovación Agroalimentaria de la Universidad Nacional de Costa Rica-Heredia.

Reactivos químicos. Se trabajó con solventes grado óptimo para cromatografía líquida de alto rendimiento (HPLC) hexano $\left(\mathrm{C}_{6} \mathrm{H}_{14}\right)$, metanol $(\mathrm{MeOH})$ y ácido acético $\left(\mathrm{CH}_{3}-\mathrm{COOH}\right)$. El estandar químico para cafeína, (-) epicatequina, teobromina, glucosa, fructosa, ácido láctico, ácido acético y etanol fue de $99 \%$ de pureza. El agua que se utilizó fue agua ultra pura desionizada.

Muestras. La cosecha de mazorcas analizada de los grupos genéticos Iquitos, Marañón, Nacional y Nanay se realizó en el Jardín Clonal Madre del Centro Agronómico Tropical de Investigación y Enseñanza (CATIE), ubicado en el Cantón de Turrialba, provincia de Cartago. También se analizaron cacaos tipo comerciales del paquete tecnológico del CATIE compuesto por 6 clones de cacao (CATIE-R1, CATIE-R4, CATIE-R6, CC-137, ICS-95 T1 y PMCT-58) e híbridos (Figura 1), los cuales son cacaos costarricenses, que se venden a mercados internacionales y nacionales, para la producción de chocolate o productos derivados. Estos cacaos se tomaron de diferentes localidades del país tales como Guatuso, Upala, Pavas de Upala y Cuatro Bocas de Upala. El tamaño de las muestras consistió en $1 \mathrm{~kg}$ de baba de mazorcas sanas y maduras, cuyas repeticiones fueron de 2 réplicas en el caso de los grupos genéticos Iquitos y Nacional del CATIE, y para las demás genéticas estudiadas 3 repeticiones (Figura 1).
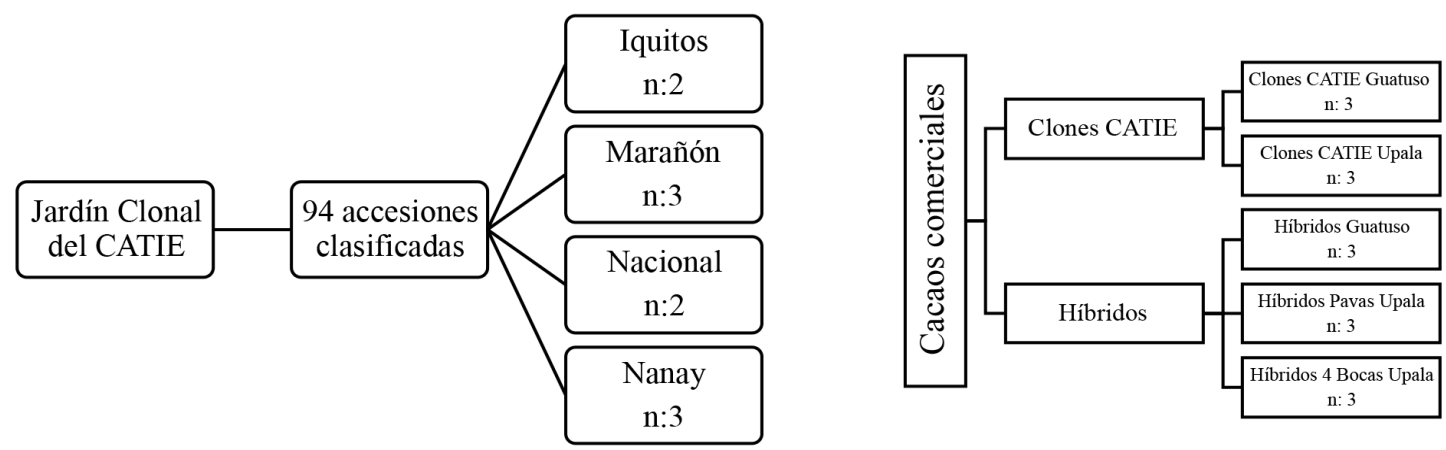

Figura 1. Muestras y repeticiones de las genéticas de cacao utilizadas en este estudio.

\section{Fermentación del cacao}

Proceso de fermentación. La metodología fue tomada de Romanens et al. (2018) con modificaciones. Se procedió a lavar las mazorcas con agua y se clasificaron de acuerdo con cada genotipo y repetición, se cortaron cuidadosamente, cerca de la base de pedúnculo, sin cortar las semillas. La extracción de las semillas en grano, se realizó sin considerar la vena central (placenta); después se colocaron y mezclaron en un recipiente hasta obtener $1 \mathrm{~kg}$. Se utilizaron 10 granos 
de cacao en un tubo cónico de $50 \mathrm{ml}$ a las $0 \mathrm{~h}$ de fermentación, para el análisis de azúcares y ácidos orgánicos en pulpa y $20 \mathrm{~g}$ de granos en otro tubo cónico para el análisis de compuestos fenólicos en grano, ambos almacenados en congelación $-20^{\circ} \mathrm{C}$. Seguidamente, se procedió a efectuar la fase anaeróbica inicial durante las primeras 48 horas. Se agregaron y mezclaron $100 \mathrm{ml}$ de suspensión de la levadura Hanseniaspora opuntiae $\left(10^{6}\right.$ UFC. $\mathrm{ml}^{-1}$ ). Posteriormente, se colocaron en una malla dentro de frascos de vidrio holgadamente tapados a temperatura ambiente $\left(24^{\circ} \mathrm{C}\right)$.

Transcurridas las $48 \mathrm{~h}$, se inició la fase aeróbica (duración 96 h). Se sacaron las mallas, se descartaron los lixiviados, se colocaron en un recipiente para agregar y mezclar $100 \mathrm{ml}$ de suspensión de Acetobacter spp. $\left(10^{6}{\text { UFC. } l^{-1}}^{-1}\right)$ y se dejó reposar por $10 \mathrm{~min}$. La suspensión de ambos cultivos iniciadores que fueron levadura y bacteria del ácido acético se prepararon en agua destilada y esterilizada, mientras su concentración fue determinada microscópicamente con un hemocitómetro. Se descartaron los lixiviados, se sacó el cacao de la malla y se procedió a incorporarlos en beakers de $1000 \mathrm{ml}$ dentro de la cámara incubadora a $32^{\circ} \mathrm{C}$ cerrada. Se programó el incremento de $4^{\circ} \mathrm{C}$ cada $12 \mathrm{~h}$, hasta llegar a una temperatura de $48^{\circ} \mathrm{C}$, la cual se mantuvo constante por 48 horas, con el fin de simular la temperatura de las fermentaciones a escala comercial para completar así, una fermentación de 6 días. Cada 24 h se monitoreó el $\mathrm{pH}$ de la pulpa, de acuerdo con la metodología de Camu et al. (2007), y consecutivamente se realizaron volteos que permitieron la aireación de la muestra. El pH de la pulpa en fermentación se determinó al insertar directamente el electrodo del potenciómetro en 3 puntos diferentes del beaker.

Además, cada $24 \mathrm{~h}$ se tomaron muestras de 10 granos en un tubo cónico para el análisis de azúcares y ácidos orgánicos en pulpa y $20 \mathrm{~g}$ de granos en otro tubo cónico para el análisis de fenólicos en grano, los cuales se almacenaron en el congelador $-20^{\circ} \mathrm{C}$ hasta sus análisis respectivos. Cumplidas las $144 \mathrm{~h}$, se retiraron los beakers de la incubadora y se procedió al secado de los granos al sol sobre bandejas plásticas por aproximadamente 4 días. Su finalización se realizó de manera visual, se consideró un secado aceptable cuando los granos se presentaron quebradizos y su cascarilla se desprendía fácilmente (Figura 2). Por último, se procedió a realizar las pruebas de corte (resultados no mostrados), para lo cual se tomaron 10 granos por muestra de cacao.

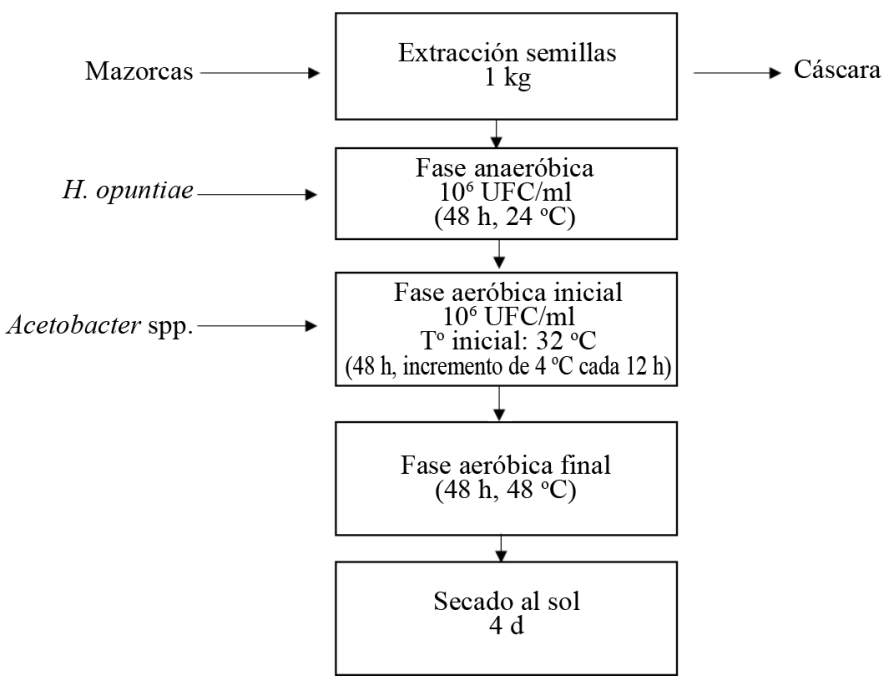

Figura 2. Diagrama del proceso de fermentación. 


\section{Análisis compuestos químicos}

Preparación de muestras. Los granos destinados, para el análisis de epicatequina y las metilxantinas (teobromina, cafeína), fueron liofilizados y desgrasadas con hexano. La extracción de tales compuestos fue basada en la metodología de Hernández-Hernández et al. (2018). Los carbohidratos, alcoholes y ácidos orgánicos se extrajeron según lo descrito por Moreira et al. (2013). Los extractos fueron filtrados con filtros de $0,45 \mu \mathrm{m}$. Finalmente, se incorporaron en viales para HPLC.

HPLC para compuestos fenólicos y metilxantinas. El análisis cromatográfico fue realizado mediante HPLC, una bomba cuaternaria, un detector de diodos (DAD) y un detector ultravioleta (UV). Los componentes fueron separados por medio de una columna ZORBAX Eclipse Plus C18 (4,6 x 100 mm, 3,5 $\mu \mathrm{m})$. El sistema solvente aplicado, fue con la metodología de Sandhya et al. (2016) ajustada a las pruebas de esta investigación. Eluente A: agua desionizada con $1 \%$ ácido acético y eluente B: acetonitrilo. El gradiente de elución se programó con un flujo de $1 \mathrm{ml} / \mathrm{min}$ de la siguiente manera: $100 \%$ A por 10 $\min ; 75 \%$ A y $25 \%$ B por $5 \mathrm{~min}, 50 \%$ A y $50 \%$ B por 2 min; $0 \%$ A y $100 \%$ B por 1 minuto; con un post-acondicionamiento de $1 \mathrm{~min}$. La detección se realizó con el DAD a longitudes de onda de $\lambda$ 275,4 nm. La identificación de los compuestos se realizó con curvas de identificación (-) de epicatequina, teobromina (mili unidades de absorbancia por segundo, $\left.\mathrm{mUA}^{*} \mathrm{~s}\right)$ y cafeína (mg.g ${ }^{-1} \mathrm{de}$ grano desgrasado).

HPLC para azúcares reductores, etanol, ácido láctico y ácido acético en pulpa. La separación de los compuestos fue igualmente efectuada con HPLC, por medio de un detector de índice de refracción (IR), según la metodología de John et al. (2016) con modificaciones, configurado con polaridad positiva y temperatura de la unidad óptica y columna de $55^{\circ} \mathrm{C}$; esto con fase móvil en la celda de referencia y un volumen de inyección de $10 \mu 1$ a través de la columna de intercambio de ligandos Hi plex-H $(3,0 \times 5,0 \mathrm{~mm}, 8 \mu \mathrm{m})$. Además, los analitos se eluyeron isocráticamente con $5 \mathrm{mM}$ de ácido sulfúrico $\left(\mathrm{H}_{2} \mathrm{SO}_{4}\right)$ grado HPLC, a un volumen de inyección de $0,6 \mathrm{ml} / \mathrm{min}$ durante $30 \mathrm{~min}$. La identificación y cuantificación de los compuestos se realizó por medio de curvas de calibración de D- $(+)$ glucosa $\left(r^{2}=0,99\right)$, fructosa $\left(r^{2}=0,99\right)$, ácido láctico $\left(\mathrm{r}^{2}=0,99\right)$ y ácido acético $\left(\mathrm{r}^{2}=0,99\right)$ (mg.g ${ }^{-1}$ pulpa).

Análisis estadístico. Para determinar el efecto de los tratamientos sobre las variables de respuesta del $\mathrm{pH}$, azúcares, ácidos orgánicos, etanol, metilxantinas y epicatequina, se realizó un análisis de varianza (ANOVA) con medidas repetidas en el tiempo, bajo la teoría de los modelos lineales mixtos. En las variables donde existieron diferencias estadísticas entre los tratamientos, se realizaron las comparaciones de medias por medio de la prueba de Prueba de Di Rienzo, Guzmán y Casanoves (DGC) $(\mathrm{p} \leq 0,05)$ lo cual permitió la formación de grupos excluyentes y no transición entre tratamientos.

\section{RESULTADOS Y DISCUSIÓN}

pH en pulpa. Todas las fermentaciones presentaron un $\mathrm{pH}$ inicial de 3,56-3,70 (0 h) y un $\mathrm{pH}$ final de 4,49-4,70 (120-144h). No se encontraron diferencias significativas en el contenido de $\mathrm{pH}$ entre los genotipos estudiados, sin embargo, a lo largo de la fermentación, sí se encontraron cambios estadísticamente significativos en función de la fase fermentativa (Figura 3). A las $72 \mathrm{~h}$, se observa la diferencia, según el comportamiento de $\mathrm{pH}$ para distinguir la fase anaeróbica de la aeróbica, la primera determinada por levaduras y LAB (bacterias ácido lácticas) en condiciones de disponibilidad limitada de oxígeno y un $\mathrm{pH}$ por debajo de 4,00 y la segunda coincide con el crecimiento de AAB (bacterias ácido acéticas), reconocidas por su potencial de oxidar etanol a ácido acético en medios neutros y ácidos (pH 4,38-4,46) (De Vuyst y Weckx 2010, Ruiz et al. 2000). 


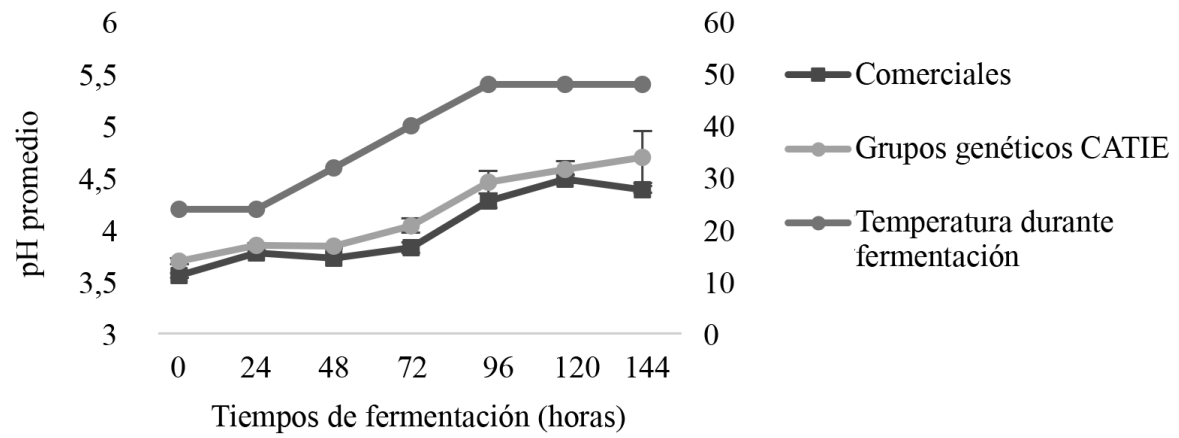

Figura 3. Comportamiento del pH en pulpa durante la fermentación en función del tiempo.

Resultados similares de $\mathrm{pH}$ (3,5 inicial, 4.0-4,3 final) han sido reportados por Camu et al. (2007) en fermentaciones espontaneas de grupos Criollo y Forasteros. Las mismas personas autoras explican que ese ligero aumento en pH se debió a que el citrato y los azúcares se convierten en ácido acético, ácido láctico y manitol.

Azúcares reductores, etanol y ácidos orgánicos en pulpa. No se encontraron diferencias significativas $(p \leq 0,05)$ en el contenido y comportamiento de azúcares, etanol y ácidos orgánicos en pulpa entre los grupos genéticos delCATIE(Figura4). Los cacaos comerciales mostraron un comportamiento similar, excepto el contenido de fructosa donde sí se encontraron diferencias significativas entre los genotipos (Figura 5). No obstante, en ambos ensayos los cambios de tales compuestos, a través del tiempo de fermentación, fueron significativamente diferentes.
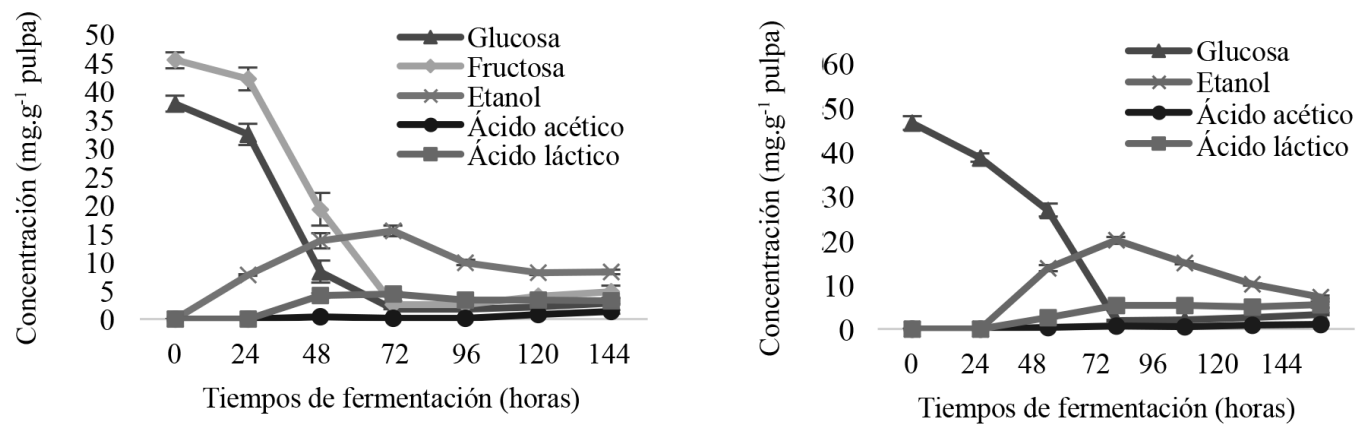

Figura 4. Comportamiento de azúcares (glucosa y fructosa), etanol y ácidos orgánicos (acético y láctico) en pulpa de los grupos genéticos del CATIE (izquierda) y cacaos comerciales (derecha) durante la fermentación en función del tiempo. 


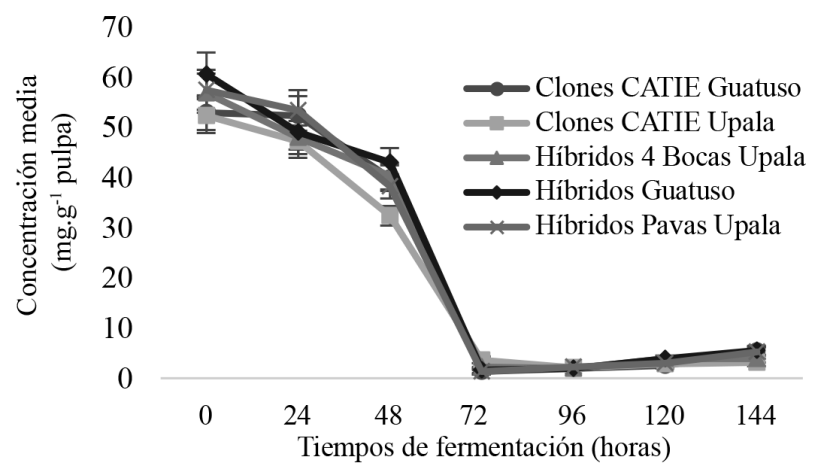

Figura 5. Comportamiento de fructosa $\left(\mathrm{mg} \mathrm{g}^{-1}\right)$ en pulpa de los cacaos comerciales durante la fermentación en función del tiempo.

La fermentación para glucosa fue de 50-38,32 mg.g ${ }^{-1}$, y para la fructosa de 60-46,06 $\mathrm{mg} \cdot \mathrm{g}^{-1}$. Ambas fueron los principales y únicos compuestos fermentables en la pulpa recién extraída $(0 \mathrm{~h})$. Estas concentraciones son consistentes con las reportadas por Papalexandratou et al. (2011) en pulpa fresca de cacaos híbridos $\left(55,7-42,8 \mathrm{mg} \cdot \mathrm{g}^{-1}\right.$ glucosa y $67,2-50,5$ mg. $\mathrm{g}^{-1}$ fructosa).

El mayor consumo de estos compuestos fue observado después de la culminación de la fase anaeróbica $(72 \mathrm{~h})$. En los grupos genéticos del CATIE (Figura 4), tanto la glucosa como la fructosa, disminuyeron sus concentraciones a $95,38 \%$ y $94,31 \%$. En el caso de los cacaos comerciales (Figura 4), también se evidenció una drástica disminución de glucosa a las $72 \mathrm{~h}$ del $96,07 \%$. Sin embargo, del comportamiento de la fructosa se obtuvieron diferentes resultados (Figura 5), lo cual confirma la hipótesis de que existen diferencias significativas entre genética y tiempo de fermentación, donde se puede observar que los Híbridos Guatuso, Híbridos Pavas de Upala, Híbridos de 4 Bocas Upala y los Clones CATIE Guatuso presentaron su disminución máxima a las $72 \mathrm{~h}$, con excepción en los Clones de Upala, cuya disminución máxima se detectó a las $96 \mathrm{~h}$.

No obstante, a pesar de las diferencias en el consumo de azúcares a través del tiempo de fermentación, la cantidad de azúcares residuales (de 2,89 mg. $\mathrm{g}^{-1}$ glucosa y $4,88 \mathrm{mg} \cdot \mathrm{g}^{-1}$ fructosa residual en grupos genéticos del CATIE, 3,24 mg.g ${ }^{-1}$ glucosa y 5,56- 3,08 mg.g ${ }^{-1}$ fructosa) coincidieron con los resultados obtenidos por Afoakwa et al. (2011), quienes reportaron cantidades residuales de azúcares no reductores de 2,03 mg.g ${ }^{-1}$, cuya disminución fue $89 \%$.

La concentración de etanol en la pulpa aumentó a las $72 \mathrm{~h}$ y luego disminuyó gradualmente a medida que progresaba la fermentación (Figura 4). Ho et al. (2014) mencionó que estas cinéticas se deben al movimiento dentro y fuera del grano. Las concentraciones máximas de etanol detectadas a las $72 \mathrm{~h}$ fueron de $19,99 \mathrm{mg} \cdot \mathrm{g}^{-1}$ en comerciales y 15,69 mg.g ${ }^{-1}$ en grupos genéticos del CATIE, lo cual coincidió con el consumo máximo de glucosa, debido a que los azúcares presentes en pulpa fueron convertidos en etanol y $\mathrm{CO}_{2}$ mediante levaduras y LAB. Diferentes investigaciones (Camu et al. 2008a, Ho et al. 2014, Lagunes-Gálvez et al. 2007, Lefeber et al. 2012, Papalexandratou et al. 2011, Thompson et al. 2013) reportaron que trascendieron concentraciones máximas de etanol en pulpa, con valores entre 5-20 mg.g ${ }^{-1}$ a valores tan altos como 30-60 mg.g $\mathrm{g}^{-1}$ (Ardhana y Fleet 2003, Roelofsen 1958, Schwan 1998).

Por otra parte, se observó una disminución gradual de etanol después de las $72 \mathrm{~h}$, resultados que coinciden con los picos más providentes de concentraciones de ácido acético obtenidas a las $144 \mathrm{~h}\left(1,01 \mathrm{mg} \cdot \mathrm{g}^{-1}\right.$ en comerciales-1,32 mg.g ${ }^{-1}$ en los grupos del CATIE) (Figura 4). La disminución 
de etanol en las últimas etapas de la fermentación se debió a su oxidación ante el ácido acético por las AAB según lo evidenciado por Camu et al. 2008a, Lagunes-Gálvez et al. 2007, Lefeber et al. 2012, Papalexandratou et al. 2011, Roelofsen 1958, y a la pérdida por evaporación a medida que aumentó la temperatura de la masa de cacao (Lagunes-Gálvez et al. 2007, Schwan y Wheals 2004).

Las cantidades de ácido acético detectadas en pulpa (Figura 4) no fueron las esperadas, ya que las fermentaciones fueron inoculadas con una bacteria ácido acética, además, según la literatura en fermentaciones de cacao en masa, la concentración de ácido acético alcanza alrededor del 2,0\% m/m (Camu et al. 2008a, Camu et al. 2008b, De Vuyst y Weckx 2010, Nielsen et al. 2007). Dicho comportamiento se pudo deber a la pérdida por evaporación (de Brito et al. 2001) y a la manifestación tardía de condiciones aptas para la expresión total de las acetobacterias, ya que como establece Afoakwa (2014) las temperaturas de $45^{\circ} \mathrm{C}$ son más favorables para el crecimiento de bacterias formadoras de ácido acético.

Las concentraciones de ácido láctico en pulpa de cacaos comerciales empezaron a detectarse partir de las 48 h (Figura 4), seguido por el alcance de concentraciones máximas de 5,31 mg. $\mathrm{g}^{-1}$ a las $72 \mathrm{~h}$, cuyas concentraciones permanecieron constantes durante la fermentación, para una concentración final de 5,45 mg. $\mathrm{g}^{-1}$. Comportamiento similar se presentó en los grupos genéticos del CATIE (Figura 4), en los cuales se alcanza una máxima concentración de 4,45 mg.g $\mathrm{g}^{-1}$ a las $72 \mathrm{~h}$, que disminuyó hasta una concentración final de 3,26 mg.g $\mathrm{g}^{-1}$ a las $144 \mathrm{~h}$. Investigaciones por Camu et al. (2007)encompassing both microbiological and metabolite target analyses. A culture-dependent (plating and incubation, followed by repetitive-sequence-based PCR analyses of picked-up colonies muestran datos similares, donde el ácido láctico alcanzó una concentración máxima de $1,0 \pm 0,06$ a 9,0 $\pm 0,06 \mathrm{mg} \cdot \mathrm{g}^{-1}$ en pulpa después de $48 \mathrm{~h}$ en fermentaciones apiladas de cacao en Gana. Según De Vuyst y Weckx (2010), las concentraciones de ácido láctico finales, detectadas en este estudio $\left(3,26 \mathrm{mg} \cdot \mathrm{g}^{-1}\right.$ grupos genéticos del CATIE y 5,45 mg. $\mathrm{g}^{-1}$ cacaos comerciales), correspondió al alcance máximo de $0,5 \% \mathrm{~m} / \mathrm{m}$ es decir, $5 \mathrm{mg} . \mathrm{g}^{-1}$ de tal compuesto de pulpa en masa fermentada de cacao.

Compuestos fenólicos y metilxantinas. El comportamiento de teobromina, en los grupos genéticos estudiados presentes en el CATIE (Figura 6), presentaron pocos cambios significativos durante los primeros días de fermentación. A las $72 \mathrm{~h}$, presentaron una disminución radical del $12,03 \%$, cuyos valores se mantuvieron constantes hasta el último día de fermentación. En el caso de los genotipos comerciales (Figura 6), sí se observaron diferencias significativas entre ellos y en función del tiempo de fermentación. Sin embargo, aunque todos presentaron diferentes cambios durante el tiempo de fermentación, todas las genéticas compartieron una disminución en el último día, así como contenidos residuales estadísticamente similares. 

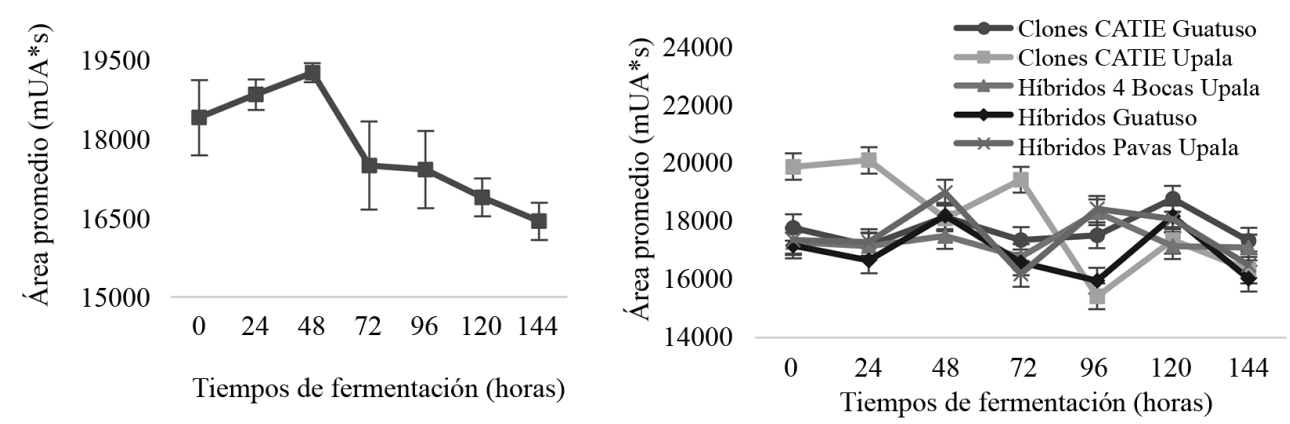

Figura 6. Comportamiento de teobromina (mUA*s) en grano de los grupos genéticos del CATIE (izquierda) y cacaos comerciales (derecha) durante la fermentación en función del tiempo.

Los cambios de cafeína resultaron sólo ser significativos a través del tiempo tanto en cacaos CATIE como los comerciales (Figura 7). Los cacaos del CATIE presentan 2,6 mg.g ${ }^{-1}$ de cafeína inicial $(0 \mathrm{~h})$, con una disminución a partir de las 24 h, cuyo contenido se mantuvo constante estadísticamente. Se detectó un contenido final a las $144 \mathrm{~h}$ de 1,9 mg.g $\mathrm{g}^{-1}$, lo cual representó un $40 \%$ de cambio. Con respecto a los cacaos comerciales, se presentaron cambios similares de $38,7 \%$, contenidos iniciales de 2,15 mg.g ${ }^{-1}$ cafeína, con un descenso a partir de las 96 h, cuya concentración final fue de 1,55 mg.g ${ }^{-1}$ cafeína. De igual manera, estudios por Brunetto et al. (2007) registraron una ligera reducción en el contenido de teobromina $(30,4 \%)$ y cafeína (45\%). Schwan y Wheals (2004) quienes explicaron que los cambios de teobromina y cafeína se deben a su difusión, así como a la pérdida en los exudados durante el proceso de fermentación (Lima et al. 2011).

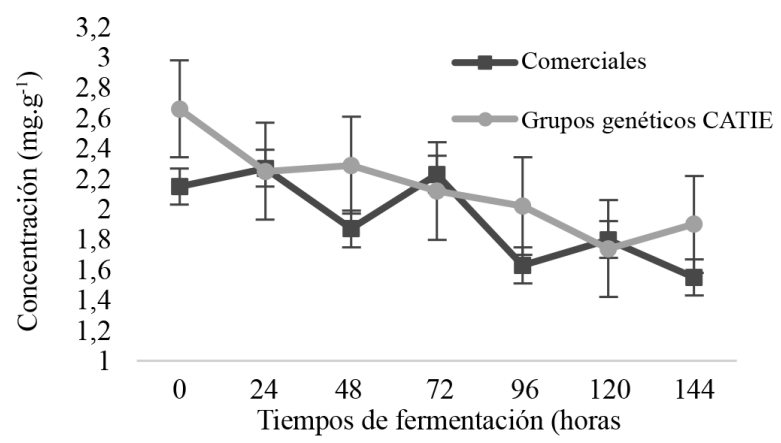

Figura 7. Comportamiento de cafeína $\left(\mathrm{mg}_{\mathrm{g}} \mathrm{g}^{-1}\right)$ en grano de los grupos genéticos del CATIE durante la fermentación en función del tiempo.

Entre los grupos genéticos del CATIE, no se presentaron diferencias significativas en contenido de epicatequina (Figura 8). Estudios expuestos por Elwers et al. (2009) y Graziani et al. (2003) tampoco reportaron diferencias significativas en el contenido de polifenoles totales y (-)-epicatequina entre diferentes genotipos de cacao. No obstante, se presentaron diferencias significativas a través de tiempo, de la cual se registró un detrimento final del 57,6\%. Datos similares fueron obtenidos con un $61,1-87,5 \%$ en el cambio final de epicatequina por Camu et al. (2008a) mediante fermentaciones apiladas. 

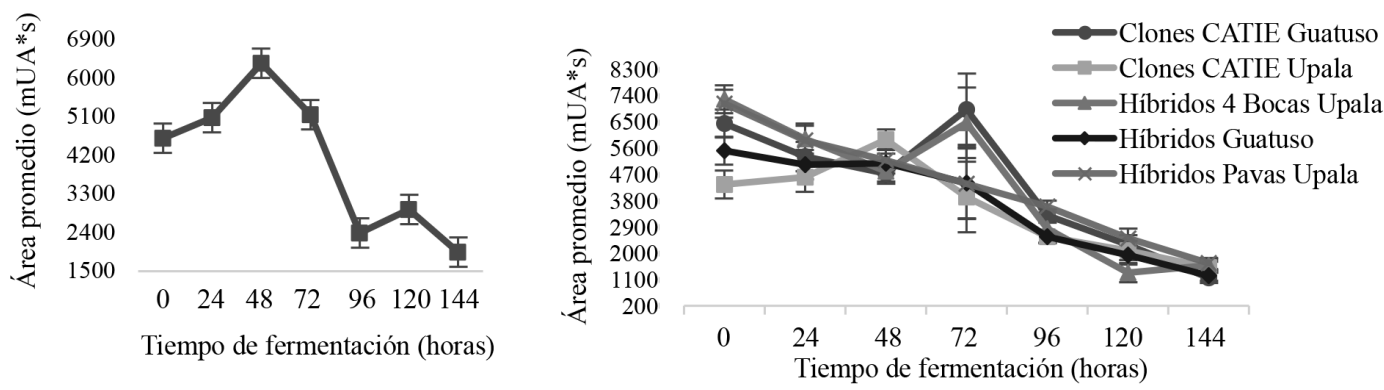

Figura 8. Comportamiento de epicatequina (mUA*s) en grano de los grupos genéticos del CATIE (izquierda) y cacaos comerciales (derecha) durante la fermentación en función del tiempo.

En el caso del comportamiento del contenido de epicatequina en los cacaos comerciales, estos sí presentaron diferencias significativas en la evolución de tal compuesto a través del tiempo y genotipo estudiado (Figura 8). Lo anterior, se podría atribuir a los diferentes factores externos, no controlados en el presente estudio, tales como localidad, condiciones edáficas y climáticas propios de cada lugar. Diferencias en el contenido de (-)- epicatequinas atribuidas a la localidad geográfica del cultivo de cacao, fueron determinados por Caligiani et al. (2007) y Keeney y Kim (1984).

Los cacaos comerciales también registraron cambios porcentuales en contenido de epicatequina al final de la fermentación (Figura 8). Los clones CATIE Guatuso presentaron el menor cambio con un $65 \%$, los Híbridos 4
Bocas de Upala con un 76,75\%, Híbridos Guatuso con $77,52 \%$ y, por último, sobresalieron los Clones CATIE Upala e Híbridos Pavas Upala con los cambios más considerables con $79,26 \%$ y 78,03\%, respectivamente. Bracco et al. 1969, Hansen et al.1998, Keeney y Kim 1984 reportaron cambios porcentuales de epicatequina a través de fermentación desde el 10-20\%, así como pérdidas de más del 70\% (Camu et al. 2008b).

Además, en ambas fermentaciones, se encontraron compuestos distintivos asociados a la genética. Para los granos de los grupos genéticos del CATIE, el contenido de epicatequina fue estadisticamente significativo en relación con los grupos genéticos estudiados, mientras que, en los cacaos comerciales, la cafeína resultó ser el compuesto distintivo estadisticamente según los genotipos (Figura 9).

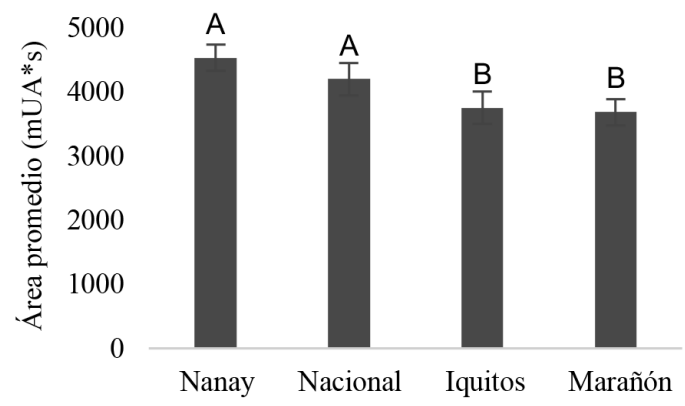

Figura 9. Contenido promedio de cafeína (mg.g $\left.{ }^{-1}\right)$ en grano durante fermentación de cacaos comerciales (izquierda) y promedio de epicatequina (mUA*s) en grano durante fermentación de los grupos genéticos del CATIE (derecha). Medias con letra común no son diferentes estadísticamente $(\mathrm{p}>0,05)$. 
Tales resultados fueron de suma importancia, ya que ambos compuestos son determinantes del sabor. En el caso de la epicatequina, se utiliza como indicador del grado de fermentación (Ferrão 2002, Forsyth y Quesnel 1963, Hansen et al. 1998). Por lo tanto, se podría aludir que los cacaos pertenecientes al grupo Nanay requieren más tiempo de fermentación que los tipo Marañon. Con respecto a los cacaos comerciales, la cafeína en los híbridos Pavas Upala fue aproximadamente $0,87 \mathrm{mg} \cdot \mathrm{g}^{-1}$ mayor que las otras muestras. La cafeína, aunque no es un compuesto determinante en el grado de fermentación, está extrechamente asociado al genotipo (Carrillo et al. 2014). Cabe señalar que la cafeína tiene gran importancia en el sabor amargo, por ende, en la calidad sensorial del chocolate. Por lo tanto, este compuesto podría ser determinante en el complejo del desarrollo de chocolates con cualidades sensoriales y nutritivas diferenciales como un mayor potencial estimulante.

\section{CONCLUSIONES}

Se concluye que la metodología de micro fermentación diseñada e implementada, en esta investigación, constituye una herramienta de utilidad y relevancia para la agroindustria del cacao. El método propuesto fue capaz de propiciar condiciones óptimas para la biotransformación de azúcares, etanol, ácido láctico y ácido acético en pulpa, así como de epicatequina y metilxantinas dentro de los granos, tal y como ocurren en la fermentación in situ del cacao. También se lograron estandarizar los comportamientos de las sucesiones microbiológicas reflejados en los cambios bioquímicos analizados en pulpa y del grano donde la temperatura, aireación y tiempo de fermentación serán claves para que las transformaciones bioquímicas se presenten de manera óptima. Además, se insta al estudio de condiciones climáticas, agronómicas del cultivo y localidad, ya que estas podrían tener un efecto importante en el comportamiento de los compuestos, tales como epicatequina, teobromina en grano.

\section{AGRADECIMIENTOS}

Las personas autoras agradecen el apoyo del CATIE por suministrar muestras del Jardín Clonal y al docente M.Sc. Alejandro Vargas Martínez por el apoyo en el análisis estadístico.

\section{LITERATURA CITADA}

Afoakwa, E. 2014. Cocoa Production and Processing Technology. Boca Raton, Estados Unidos, CRC Press. 374 p.

Afoakwa, EO; Paterson, A; Fowler, M; Ryan, A. 2008. Flavor formation and character in cocoa and chocolate: A critical review. Critical Reviews in Food Science and Nutrition 48(9):840-857.

Afoakwa, EO; Quao, J; Takrama, J; Budu, AS; Saalia, FK. 2011. Effect of pulp preconditioning on acidification, proteolysis, sugars and free fatty acids concentration during fermentation of cocoa (Theobroma cacao) beans. International Journal of Food Sciences and Nutrition 62(7):755-764.

Ardhana, MM; Fleet, GH. 2003. The microbial ecology of cocoa bean fermentations in Indonesia. International Journal of Food Microbiology (86):87-99.

Bartley, BG. 2005. The genetic diversity of cacao and its utilization. London, Reino Unido, CABI. 337 p.

Bracco, U; Grailhe, N; Egli, RH. 1969. Cocoa Curing in the Ivory Coast. Journal of the Science of Food and Agriculture 20:713-717.

Brunetto, R; Gutie, L; Ramos, G; Romero, C; Zambrano, A; Go, A. 2007. Determination of theobromine, theophylline and caffeine in cocoa samples by a high-performance liquid chromatographic method with on-line sample cleanup in a switching-column system. Food Chemistry 100:459-467.

Caligiani, A; Cirlini, M; Palla, G; Ravaglia, R; Arlorio, M. 2007. GC-MS Detection of Chiral Markers in Cocoa Beans of Different Quality and Geographic Origin. Chirality (19):329-334.

Camu, N; De Winter, T; Addo, SK; Takrama, JS; Bernaert, H; De Vuyst, L. 2008a. Fermentation of cocoa beans: influence of microbial activities and polyphenol concentrations on the flavour of chocolate. Journal of the Science of Food and Agriculture (88):2288-2297.

Camu, N; De Winter, T; Verbrugghe, K; Cleenwerck, I; Vandamme, P; Takrama, JS; Vancanneyt, M; De Vuyst, L. 2007. Dynamics and biodiversity of populations of lactic acid bacteria and acetic acid bacteria involved in spontaneous heap fermentation of cocoa beans in Ghana. Applied and Environmental Microbiology 73(6):1809-1824. 
Camu, N; González, Á; De Winter, T; Van Schoor, A; De Bruyne, K; Vandamme, P; Takrama, JS; Addo, SK; De Vuyst, L. 2008b. Influence of turning and environmental contamination on the dynamics of populations of lactic acid and acetic acid bacteria involved in spontaneous cocoa bean heap fermentation in Ghana. Applied and Environmental Microbiology 74(1):86-98.

Carrillo, LC; Londoño-Londoño, J; Gil, A. 2014. Comparison of polyphenol, methylxanthines and antioxidant activity in Theobroma cacao beans from different cocoa-growing areas in Colombia. Food Research International 60:273-280.

Contreras, C; Ortiz de Bertorelli, L; Graziani de Fariñas, L; Parra, P. 2002. Fermentadores para cacao usados por los productores de la localidad de Cumboto, Venezuela. Agronomía Tropical 54(2):219-232.

Cros, E; Jeanjean, J. 1995. Cocoa quality: Effect of fermentation and drying. Plantations Reach Development (5):25-27.

de Brito, ES; Garcia, NHP; Gallao, MI; Cortelazzo, AL; Fevereiro, PS; Braga, MR. 2001. Structural and chemical changes in cocoa (Theobroma cacao L) during fermentation, drying and roasting. Journal of the Science of Food and Agriculture 81(2):281-288.

De Vuyst, L; Weckx, S. 2010. The functional role of lactic acid bacteria in cocoa bean fermentation. In Mozzi, F; Raya, RR; Vignolo, GM (eds.). Biotechnology of Lactic Acid Bacteria: Novel Applications. EE. UU., Blackwell-Wiley. p. 301-326.

Elwers, S; Zambrano, A; Rohsius, C; Lieberei, R. 2009. Differences between the content of phenolic compounds in Criollo, Forastero and Trinitario cocoa seed (Theobroma cacao L.). European Food Research and Technology 229(6):937-948.

Ferrão, JE. 2002. Cacau: tecnologia pós-colheita. Lisboa, Portugal, Instituto de Cooperação PortuguesaMinistério da Agricultura, do Desenvolvimento Rural e das Pescas. 348 p.

Forsyth, W; Quesnel, V. 1963. The mechanism of cacao curing. Advances in Enzymology and Related Areas of Molecular Biology (25):457-492.

Graziani de Fariñas, L; Ortiz de Bertorelli, L; Parra, P. 2003. Características químicas de la semilla de diferentes tipos de cacao de la localidad de Cumboto, Aragua. Agronomía Tropical 53(2):133-144.

Hansen, CE; del Olmo, M; Burri, C. 1998. Enzyme activities in cocoa beans during fermentation. Journal of the Science of Food and Agriculture 77(2):273-281.

Hernández-Hernández, C; Viera-Alcaide, I; Morales, AM; Fernández-Bolaños, J; Rodríguez-Gutiérrez, G. 2018. Bioactive compounds in Mexican genotypes of cocoa cotyledon and husk. Food Chemistry 240:831-839.
Ho, VTT; Zhao, J; Fleet, G. 2014. Yeasts are essential for cocoa bean fermentation. International Journal of Food Microbiology 174:72-87.

John, WA; Kumari, N; Böttcher, NL; Koffi, KJ; Grimbs, S; Vrancken, G; D’Souza RN; Kuhner, N; Ullrich, MS 2016. Aseptic artificial fermentation of cocoa beans can be fashioned to replicate the peptide profile of commercial cocoa bean fermentations. Food Research International 89:764-772.

Keeney, PG; Kim, H. 1984. (-)-Epicatechin Content in Fermented and Unfermented, Journal of Food Science 49:1090-1092.

Kongor, JE; Hinneh, M; Van de Walle, D; Afoakwa, EO; Boeckx, P; Dewettinck, K. 2016. Factors influencing quality variation in cocoa (Theobroma cacao) bean flavour profile - A review. Food Research International 82:44-52.

Lagunes-Gálvez, S; Loiseau, G; Paredes, JL; Barel, M; Guiraud, JP. 2007. Study on the microflora and biochemistry of cocoa fermentation in the Dominican Republic. International Journal of Food Microbiology 114:124-130.

Lefeber, T; Gobert, W; Vrancken, G; Camu, N; De Vuyst, L. 2011. Dynamics and species diversity of communities of lactic acid bacteria and acetic acid bacteria during spontaneous cocoa bean fermentation in vessels. Food Microbiology 28(3):457-464.

Lefeber, T; Papalexandratou, Z; Gobert, W; Camu, N; De Vuyst, L. 2012. On-farm implementation of a starter culture for improved cocoa bean fermentation and its influence on the flavour of chocolates produced thereof. Food Microbiology 30:379-392.

Lima, LJ; Almeida, MH; Rob Nout, MJ; Zwietering, MH. 2011. Theobroma cacao L., "The Food of the Gods": Quality determinants of commercial cocoa beans, with particular reference to the impact of fermentation. Critical Reviews in Food Science and Nutrition 51(8):731-761.

Moreira, IM; Miguel, MG; Duarte, WF; Dias, DR; Schwan, RF. 2013. Microbial succession and the dynamics of metabolites and sugars during the fermentation of three different cocoa (Theobroma cacao L.) hybrids. Food Research International 54:9-17.

Motamayor, C; Lachenaud, P; da Silva e Mota, JW; Loor, R; Kuhn, ND; Brown, JS; Schnell, RJ. 2008. Geographic and genetic population differentiation of the amazonian chocolate tree (Theobroma cacao L). PLoS ONE 3(10):3311.

N'Goran, JA; Laurent, V; Risterucci, AM; Lanaud, C. 1994. Comparative genetic diversity studies of Theobroma cacao L. using RFLP and RAPD markers. Heredity 73(6):589-597.

Nielsen, DS; Teniola, OD; Ban-Koffi, L; Owusu, M; Andersson, TS; Holzapfel, WH. 2007. The microbiology of Ghanaian cocoa fermentations analysed using culture-dependent and culture- 
independent methods. International Journal of Food Microbiology 114:168-186.

Oberthür, T; Läderach, P; Posada, H; Fisher, MJ; Samper, LF; Illera, J; Usma, H; Perez, C; Jarvis, A. 2011. Regional relationships between inherent coffee quality and growing environment for denomination of origin labels in Nariño and Cauca, Colombia. Food Policy 36:783-794.

Papalexandratou, Z; Vrancken, G; De Bruyne, K; Vandamme, P; De Vuyst, L. 2011. Spontaneous organic cocoa bean box fermentations in Brazil are characterized by a restricted species diversity of lactic acid bacteria and acetic acid bacteria. Food Microbiology 28:1326-1338.

Roelofsen, PA. 1958. Fermentation, drying and storage of cocoa beans. Advances in Food Research 8:225-299.

Romanens, E; Näf, R; Lobmaier, T; Pedan, V; Leischtfeld, SF; Meile, L; Schwenninger, SM. 2018. A lab-scale model system for cocoa bean fermentation. Applied Microbiology and Biotechnology 102:3349-3362.

Ruiz, A; Poblet, M; Mas, A; Guillamón, M. 2000. Identification of acetic acid bacteria by RFLP of PCR-amplified 16S rDNA and $16 \mathrm{~S}-23 \mathrm{~S}$ rDNA intergenic spacer. International Journal of Systematic and Evolutionary Microbiology 50:1981-1987.

Sandhya, MVS; Yallappa, BS; Varadaraj, MC; Puranaik, J; Rao, LJ; Janardhan, P; Murthy, PS. 2016. Inoculum of the starter consortia and interactive metabolic process in enhancing quality of cocoa bean (Theobroma cacao) fermentation. LWT - Food Science and Technology 65:731-738.

Schwan, R; Wheals, A. 2004. The microbiology of cocoa fermentation and its role in chocolate quality. Critical Review. Food Science and Nutrition 44:205-221.

Schwan, RF. 1998. Cocoa fermentations conducted with a defined microbial cocktail inoculum. Applied and Environmental Microbiology 64(4):1477-1483.

Thompson, SS; Miller, KB; Lopez, A; Camu, N. 2013. Cocoa and coffee. In Food microbiology: fundamentals and frontiers. 4 ed. Washington, USA, ASM Press. p. $881-889$. 
